\title{
Postimplantation morphologic changes of glutaraldehyde-fixed porcine aortic roots and risk of aneurysm and rupture
}

Tirone E. David, MD, Susan Armstrong, MSc, Manjula Maganti, MSc, Jagdish Butany, MD, Christopher M. Feindel, MD, and Joanne Bos, RN

Objective: Rupture of glutaraldehyde-fixed porcine aortic roots has been reported, but the mechanism and incidence of this complication is unknown. This study evaluates the clinical outcomes and the risk of dilation and rupture of porcine aortic roots after implantation.

Methods: Commercially available porcine aortic roots were used for aortic root replacement in 308 patients (Freestyle bioprosthesis [Medtronic, Minneapolis, Minn] in 251 patients and Toronto Root [St Jude Medical, St Paul, Minn] in 57 patients) whose mean age was $62 \pm 13$ years. The main indication for aortic root replacement was dilation of the native aortic root. Clinical follow-up was complete at a mean of $5.3 \pm 2.5$ years. Valve function and aortic root diameter were assessed by means of echocardiography.

Results: There were $10(3.2 \%)$ operative and $39(12.6 \%)$ late deaths. At 8 years, patients' survival was $79.0 \% \pm$ $3.1 \%$, freedom from reoperation was $95.3 \% \pm 1.7 \%$, and freedom from severe aortic insufficiency was $93.8 \% \pm$ $2.7 \%$. The diameter of the aortic sinuses increased from $31.9 \pm 4.3$ to $34.1 \pm 4.8 \mathrm{~mm}(P<.0001)$, and it exceeded $40 \mathrm{~mm}$ in $10 \%$ of the patients. Linear regression analysis revealed that the duration of follow-up $(P<.0001)$ and the size of the valve implanted $(P<.0001)$ were associated with risk of sinus dilation. There was only 1 early rupture of the noncoronary aortic sinus and 2 late aneurysms that required repeat operations. Histologic examination of explanted aneurysmal porcine roots revealed marked changes in the xenograft arterial wall, with abundant mononuclear cells suggestive of immunologic reaction.

Conclusions: Mild dilation of porcine aortic roots after aortic root replacement is common, but aneurysm formation and rupture are rare during the first decade of follow-up. Annual surveillance with echocardiography is recommended.

Glutaraldehyde-fixed porcine aortic roots were introduced for clinical use in the early 1990s and have gained widespread use in the treatment of patients with aortic root and aortic valve disease. ${ }^{1-3}$ In North America, the Medtronic Freestyle bioprosthesis (Medtronic, Minneapolis, Minn) has been commercially available for almost 1 decade. The Toronto Root bioprosthesis (St Jude Medical, St Paul, Minn) was only used under an investigational device exemption, and the company decided to discontinue its manufacturing in early 2007.

Porcine aortic roots have excellent hemodynamic features that resemble those of aortic valve homografts. ${ }^{3-5}$ Moreover, a randomized clinical trial on aortic root replacement (ARR) comparing aortic valve homografts with the Medtronic Freestyle bioprosthesis showed that the calcium content in the arterial wall, as well as in the aortic cusps, is lower in porcine aortic roots than in homograft aortic roots. ${ }^{5,6}$ In addition, the clinical results of aortic valve replacement, as well as ARR, with porcine aortic roots have been reported to be excel-

From the Division of Cardiovascular Surgery of the Peter Munk Cardiac Centre and the Department of Pathology of Toronto General Hospital and University of Toronto, Toronto, Ontario, Canada.

Received for publication March 4, 2008; revisions received June 24, 2008; accepted for publication July 2, 2008.

Address for reprints: Tirone E. David, MD, 200 Elizabeth St 4N457, Toronto, Ontario M5G 2C4, Canada (E-mail: tirone.david@uhn.on.ca).

J Thorac Cardiovasc Surg 2009;137:94-100

$0022-5223 / \$ 36.00$

Copyright (c) 2009 by The American Association for Thoracic Surgery doi:10.1016/j.jtcvs.2008.07.004 lent. ${ }^{1,2}$ It is generally believed that the technique of ARR is associated with a lower risk of aortic insufficiency (AI) and valve failure than the technique of subcoronary implantation. ${ }^{1}$ For these reasons, some surgeons use exclusively the technique of ARR to treat patients with aortic valve disease with normal or abnormal aortic sinuses. ${ }^{2}$

The fate of the porcine arterial wall when used for ARR is largely unknown. ${ }^{7,8}$ There are case reports of rupture of the porcine aortic sinuses when used for ARR. ${ }^{9-12}$

This study was undertaken to examine the clinical outcomes, risk of dilation, aneurysm formation, and rupture of glutaraldehyde-fixed porcine aortic roots after ARR.

\section{MATERIALS AND METHODS}

Commercially available porcine aortic roots were used for ARR in 308 patients whose mean age was $62 \pm 13$ years. The Freestyle bioprosthesis was used in 251 patients, and the Toronto Root bioprosthesis was used in 57 patients. Table 1 shows the clinical profile of all patients. The main indication for ARR was dilation of the aortic root, which was mostly caused by bicuspid aortic valve disease, as seen in Table 1 . Table 2 shows the operative data.

\section{Operative Techniques}

The ascending aorta was transected approximately $2 \mathrm{~cm}$ above the origin of the coronary arteries, and the noncoronary aortic sinus was incised down to the level of the aortic annulus to enhance exposure of the aortic root. The native or prosthetic aortic valve was excised, and the aortic annulus was measured to select the valve size. Next, myocardial revascularization and other intracardiac repairs were carried out as needed. 


\section{Abbreviations and Acronyms \\ AI $=$ aortic insufficiency \\ $\mathrm{ARR}=$ aortic root replacement \\ PVE $=$ prosthetic valve endocarditis \\ SVD $=$ structural valve deterioration}

In 67 patients the porcine aortic root was implanted by using the aortic root inclusion technique. The porcine aortic root was secured to the aortic annulus either with multiple interrupted sutures of 4-0 polyester or with continuous 3-0 polypropylene sutures. The graft was implanted in its anatomic position in 42 patients and rotated $120^{\circ}$ in 25 patients to match the level of the right coronary artery of the recipient because this artery in the porcine root is fairly high. Round openings of 8 to $10 \mathrm{~mm}$ in diameter were created in the xenograft, and the aortic sinus wall around the left and right coronary arteries of the patient was sutured to the xenograft with continuous 5-0 polypropylene sutures. Both the porcine root and the patient's remaining aortic root were trimmed as needed and sutured to the remaining ascending aorta in 39 patients or to an interposed tubular Dacron graft in 28 patients. The incision in the noncoronary aortic sinus of the patient was loosely approximated with 1 or 2 interrupted sutures after administration of protamine and hemostasis.

\section{TABLE 1. Clinical profile of patients}

\begin{tabular}{lc}
\hline Age & \\
Mean \pm SD (y) & $62 \pm 13$ \\
Range & $17-86$ \\
Sex & \\
$\quad$ Male & $225(73)$ \\
Female & $83(27)$ \\
Clinical symptoms & \\
Syncope & $21(7)$ \\
Angina pectoris & $89(29)$ \\
Congestive heart failure & $104(34)$ \\
New York Heart Association functional class & \\
I & $37(12)$ \\
II & $120(39)$ \\
III & $98(32)$ \\
IV & $53(17)$ \\
Associated diseases & \\
Diabetes & $25(8)$ \\
Hypertension & $135(44)$ \\
Chronic obstructive lung disease & $6(2)$ \\
Renal failure & $4(1)$ \\
Peripheral vascular disease & $8(3)$ \\
Stroke/TIA & $14(5)$ \\
Active infective endocarditis & $6(2)$ \\
Previous aortic valve surgery & $44(14)$ \\
Aortic root and/or ascending aorta $>45$ mm & \\
Coronary artery disease & $98(32)$ \\
Mitral valve disease & $24(8)$ \\
Tricuspid insufficiency + stenosis & 1 \\
Atrial septal defect & 2 \\
Ventricular septal defect & 2 \\
Hypertrophic obstructive cardiomyopathy & $8(3)$ \\
\hline
\end{tabular}

Percentages are shown in parentheses. $S D$, Standard deviation; TIA, transient ischemic attack.
TABLE 2. Operative data

\begin{tabular}{lc}
\hline Aortic root pathology & \\
Bicuspid or other congenital & $170(55)$ \\
Degenerative calcific & $52(17)$ \\
Annuloaortic ectasia & $29(9)$ \\
Acute aortic dissection & $5(2)$ \\
Rheumatic & $3(1)$ \\
Prosthetic aortic valve/root & $41(13)$ \\
Miscellaneous & $8(3)$ \\
Bioprosthetic aortic root implanted & \\
Medtronic Freestyle & $251(71)$ \\
Toronto Root & $57(18)$ \\
Bioprosthetic aortic root annular size (mm) & \\
19 & 1 \\
21 & $7(2)$ \\
23 & $27(9)$ \\
25 & $55(18)$ \\
27 & $141(46)$ \\
29 & $77(25)$ \\
Other procedures & \\
Coronary artery bypass & $98(32)$ \\
Septal myectomy & $8(3)$ \\
Mitral valve repair & $20(6)$ \\
Mitral valve replacement with annular reconstruction & 2 \\
Tricuspid valve annuloplasty & 1 \\
Atrial septal defect closure & 2 \\
Ventricular septal defect closure & 2 \\
Replacement of the ascending aorta & $89(29)$ \\
Replacement of the transverse arch & $24(8)$ \\
Aortic clamping time \pm SD (min) & $101 \pm 36$ \\
Cardiopulmonary bypass time \pm SD (min) & $130 \pm 52$ \\
Hospital stay \pm SD (d) & $9.0 \pm 7.7$ \\
\hline &
\end{tabular}

Percentages are shown in parentheses. $S D$, Standard deviation.

In 241 patients the porcine aortic root was implanted by using the technique of ARR. The aortic root of the patient was excised, leaving 5 to $6 \mathrm{~mm}$ of aortic sinus wall around each coronary artery. The xenograft root was implanted in its anatomic position in 204 patients and rotated $120^{\circ}$ in 37 patients to better match the level of the right coronary artery of the patient Round openings of 6 to $8 \mathrm{~mm}$ were made in the porcine sinuses, and the coronary arteries were reimplanted with continuous 5-0 polypropylene sutures. The distal arterial wall of the xenograft was sutured to the mid or distal ascending aorta in 180 patients and to a tubular Dacron graft in 61 patients with continuous 4-0 polypropylene sutures. Tisseel (Baxter, Deerfield, Ill) was used around the coronary artery buttons in 19 patients. BioGlue (Cryolife, Kennesaw, Ga), "French glue,'” or any other synthetic glue was never used.

All patients were discharged on aspirin or aspirin and warfarin sodium if they were in atrial fibrillation.

\section{Follow-up}

Patients who received the Toronto Root bioprosthesis had clinical evaluation and transthoracic echocardiographic analysis annually in our institution. Patients who received the Medtronic Freestyle bioprosthesis had an echocardiogram before discharge from our hospital and were followed by the referring cardiologists, who obtained an echocardiogram to assess valve and ventricular function. Forty-three patients with the Toronto Root bioprosthesis and 158 patients with the Freestyle bioprosthesis had a late study in our institution to measure the diameter of the porcine root. The mean duration of clinical follow-up was $5.3 \pm 2.5$ years and was $100 \%$ complete. 


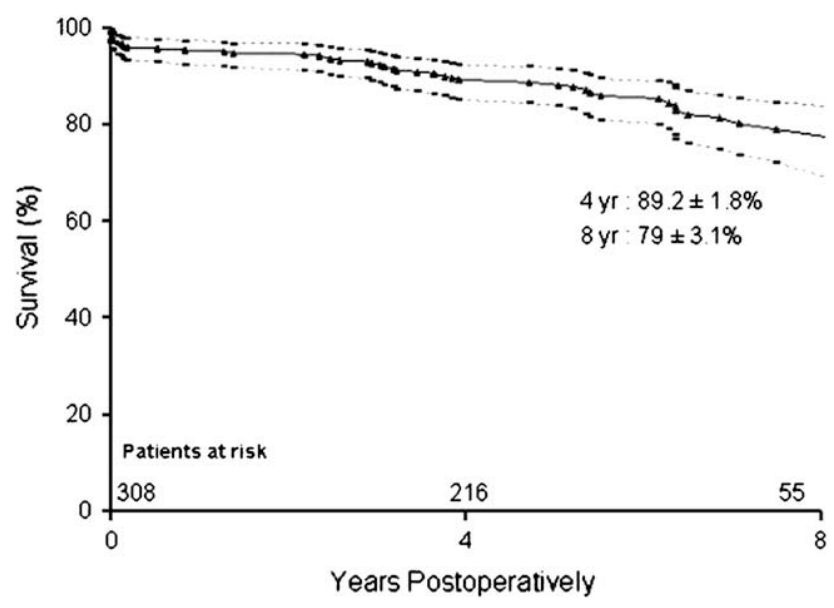

FIGURE 1. Survival after aortic root replacement with porcine aortic roots.

The mean duration of echocardiographic assessments of the porcine aortic root diameter in 201 patients was $5.3 \pm 2.1$ years.

\section{Statistical Analyses}

All data analyses were performed with SAS 9.1 Software (SAS Institute, Inc, Cary, NC). Categorical variables were reported as frequencies, and all continuous variables were reported as the mean \pm standard deviation. Logistic regression analysis was used to determine independent predictors of operative deaths. The Kaplan-Meier method was used to calculate estimates for long-term survival, freedom from reoperation, and freedom from severe AI. All preoperative variables with a univariate $P$ value of less than .25 or those with known biologic significance but failing to meet this critical $\alpha$ level were submitted to the multivariable model for Cox regression analysis to determine the independent predictors of operative and late death. Repeated measurements analysis was used to examine the differences between early and late postoperative echocardiographic measurements of the porcine aortic root. Multivariable linear regression methods were used to evaluate the possible association of preoperative variables, valve size, technique of implantation, replacement of the ascending aorta, and duration of echocardiographic follow-up with dilation of the aortic sinuses.

\section{RESULTS}

\section{Clinical Outcomes}

There were $10(3.2 \%)$ operative deaths. The noncoronary aortic sinus of a Freestyle aortic root ruptured intraoperatively as the chest was being closed in an elderly patient during a brief hypertensive episode, and it was successfully repaired with an autologous pericardial patch. This patient died of pneumonia 9 months later with an echocardiographically intact porcine aortic root. Logistic regression analysis identified functional class IV as a single independent predictor of operative mortality (odds ratio, 10; 95\% confidence limits, 2-40).

There were 39 late deaths: 6 valve-related deaths (3 strokes, 2 prosthetic valve endocarditis [PVE], and 1 structural valve deterioration [SVD]), 7 cardiac-related deaths ( 3 sudden deaths, 1 myocardial infarction, and 3 congestive heart failure), and 26 deaths of other causes. All 3 patients who died suddenly were elderly with known coronary artery

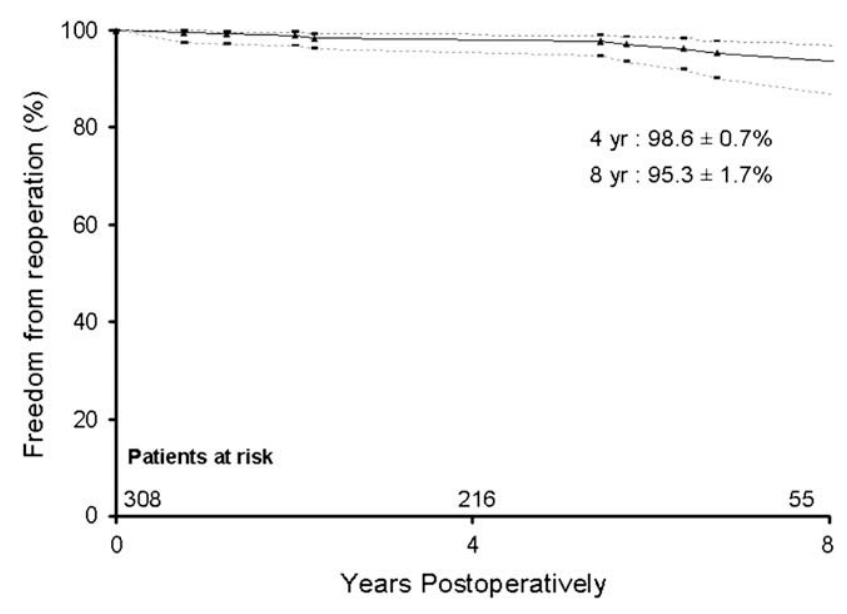

FIGURE 2. Freedom from reoperation.

disease, and the death was believed to be due to dysrhythmias, myocardial infarction, or both. Cox regression analysis identified age by increments of 5 years (hazard ratio, 1.39; $95 \%$ confidence limits, 1.19-1.63), left ventricular ejection fraction of less than $40 \%$ (hazard ratio, 2.40; $95 \%$ confidence limits, $1.27-4.55$ ), and redo cardiac surgery (hazard ratio, 2.72; 95\% confidence limits, 1.46-5.27) as independent predictors of death of all causes. Figure 1 shows the patients' survival.

Twelve patients required reoperation: 2 for PVE, 1 for detachment of the right coronary artery implantation, and 9 for SVD. The 2 cases of PVE occurred at 19 and 20 months after the operation, respectively. The partial detachment of the right coronary artery reimplantation was diagnosed 7 months after the operation during a routine echocardiographic study in a patient in whom the aortic root inclusion technique had been used, and at the time of the operation, a tear was found in the right aortic sinus of the porcine root along the sutured line, probably caused by excessive tension. The patients with SVD had 1 aneurysm of the porcine aortic root of $50 \mathrm{~mm}$ in diameter with severe AI without cusp tears 5 years after implantation, 1 aneurysm of $48 \mathrm{~mm}$ in diameter with severe AI caused by a cusp tear 9 years after the operation, 6 cases of severe AI caused by cusp tear without significant dilation of the root ranging from 3 to 9 years after implantation, and 1 aortic stenosis caused by severe calcification at 9 years. Ten of 12 reoperations were done in our hospital, and 2 patients died (1 of endocarditis and 1 of SVD). Figure 2 shows the freedom from reoperation.

Six patients had PVE: 2 underwent reoperations (1 died), and 4 were treated with antibiotics alone (1 died during treatment, 1 died suddenly 4 months after successful medical therapy, and 2 were alive at the last follow-up). In 2 patients who had surgical intervention for PVE, the infection was limited to the cusps in one, and the other had an aortic root abscess.

Seventeen patients had thromboembolic complications (6 transient ischemic attacks and 11 strokes). At the most recent 


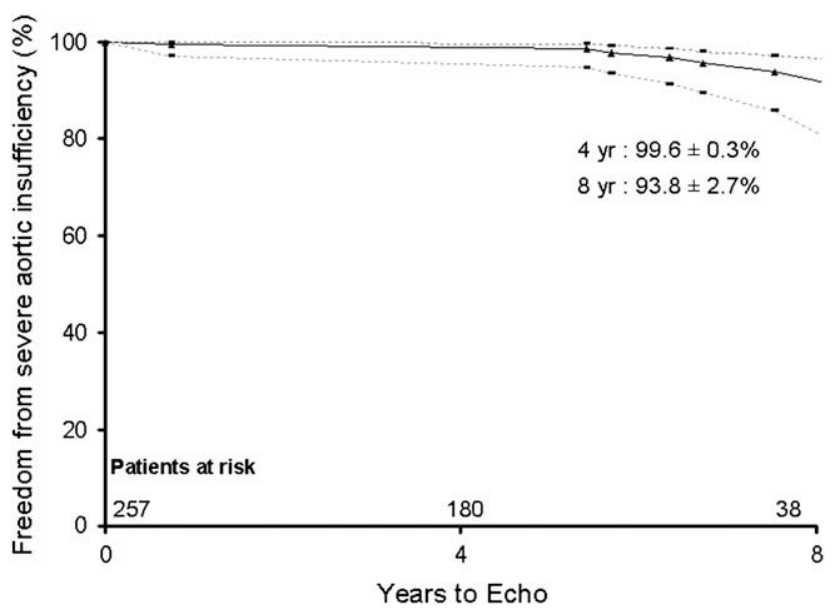

FIGURE 3. Freedom from severe aortic insufficiency.

follow-up contact, 35 patients were taking warfarin sodium, 171 taking aspirin, and 43 were not taking either anticoagulant or antiplatelet agent.

Eight patients had severe AI, and 1 patient had mild-tomoderate AI. All 8 patients with severe AI underwent reoperation. Dilation of the porcine aortic root (aortic sinuses of 48 and $50 \mathrm{~mm}$ and sinotubular junctions of 39 and $43 \mathrm{~mm}$, respectively) was the cause of AI in 2 patients. Figure 3 shows the freedom from severe AI.

At the latest follow-up, 249 patients were alive and had their original porcine aortic roots, and $183(73 \%)$ were in functional class I, $38(15 \%)$ were in class II, $27(11 \%)$ were in class III, and 1 were in class IV.

\section{Morphologic Changes in the Porcine Aortic Root}

Table 3 summarizes the internal diameter of the aortic sinuses of the porcine aortic root 1 week after the operation and at the latest echocardiographic study. Both Freestyle and Toronto Root bioprostheses dilated after implantation. The diameters of the aortic sinuses decreased by more than $2 \mathrm{~mm}$ in 32 patients, did not change $( \pm 2 \mathrm{~mm})$ in 77 patients, and increased by more than $2 \mathrm{~mm}$ in 92 patients. Figure 4 shows the diameters of the porcine aortic sinuses according to valve sizes at various time intervals. Linear regression analysis revealed that the duration of follow-up $(P<.0001)$ and the size of the implanted valve $(P<.0001)$ were associated with the risk of aortic sinus dilation. The diameter of the porcine aortic sinuses exceeded $40 \mathrm{~mm}$ in $20(10 \%)$ patients. In these 20 patients the diameters increased from $36.0 \pm 3.2 \mathrm{~mm}$ in the early postoperative period to $43.0 \pm 2.8 \mathrm{~mm}$ in the late postoperative period $(P<.0001)$, as shown in Figure 5 .

\section{Histologic Examination of Explanted Porcine Aortic Roots}

Histologic examination of 2 explanted aneurysmal porcine aortic roots revealed marked changes in the arterial wall with mononuclear cells (macrophages, lymphocytes, and plasma cells), which is highly suggestive of "digestion", of the arterial wall by an immune-mediated response. In addition, there was histologic evidence of thinning of the xenograft arterial wall areas and of full-thickness loss of medial smooth muscle and replacement by connective tissue in areas where dilation occurred (Figure 6). Inflammatory reactions of variable degree were seen around the arterial wall of the xenograft in all explanted aortic roots. Similar changes were seen at multiple points in the porcine aortic root.

\section{DISCUSSION}

The clinical outcomes in this series of ARR with porcine aortic roots are similar to those reported by others. ${ }^{1-3,7}$ The results of a multicenter study on the Freestyle bioprosthesis showed no SVD at 8 years when this valve was used for ARR, ${ }^{13}$ but in a subsequent report on the same series, the freedom from SVD was $96 \% \pm 4.5 \%$ at 10 years. ${ }^{1}$ However, in none of these longitudinal studies is there mention of dilation or rupture of the porcine aortic root. ${ }^{1-3,7,13}$

The first report of rupture of a porcine aortic root that we could find in our review was by Kameda and associates. 9 Those investigators described ARR with a Freestyle bioprosthesis in a patient with an aortic root aneurysm. The patient bled postoperatively, and methyl 2-cyanocrylate glue was used to accomplish hemostasis. Fifteen months later, the patient presented in shock because of a ruptured xenograft root with a false aneurysm and fistula into the pulmonary artery. The authors suspected that the cause for the rupture of the porcine aortic root was trauma of the xenograft and the use of methyl 2-cyanocrylate glue at the initial operation. More recently, Ozaki and colleagues ${ }^{10}$ described 4

TABLE 3. Internal diameters of the aortic sinuses of the porcine aortic root early and late after implantation

\begin{tabular}{|c|c|c|c|c|c|c|}
\hline \multirow[b]{2}{*}{ Valve size $(\mathrm{mm})$} & \multirow[b]{2}{*}{ No. of patients } & \multicolumn{2}{|c|}{ Early diameter } & \multicolumn{2}{|c|}{ Late diameter } & \multirow[b]{2}{*}{$P$ value } \\
\hline & & Mean & Range & Mean & Range & \\
\hline 21 & 2 & $26.5 \pm 0.7$ & $26-27$ & $31.5 \pm 0.7$ & $31-32$ & - \\
\hline 23 & 16 & $28.3 \pm 3.7$ & $20-34$ & $29.5 \pm 4.9$ & $21-37$ & .41 \\
\hline 25 & 34 & $29.0 \pm 4.8$ & $19-38$ & $31.7 \pm 4.3$ & $24-41$ & .001 \\
\hline 27 & 102 & $32.4 \pm 3.7$ & $25-43$ & $34.6 \pm 4.6$ & $26-48$ & .000 \\
\hline 29 & 47 & $34.2 \pm 3.1$ & $26-40$ & $36.7 \pm 4.1$ & $29-50$ & .000 \\
\hline All sizes & 201 & $31.9 \pm 4.3$ & $19-43$ & $34.2 \pm 4.9$ & $21-50$ & .000 \\
\hline
\end{tabular}


Size of im planted aortic valve $=23 \mathrm{~m} \mathrm{~m}$

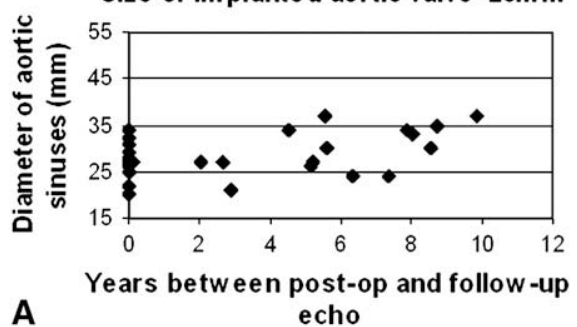

Size of im planted aortic valve $=27 \mathrm{~m} \mathrm{~m}$
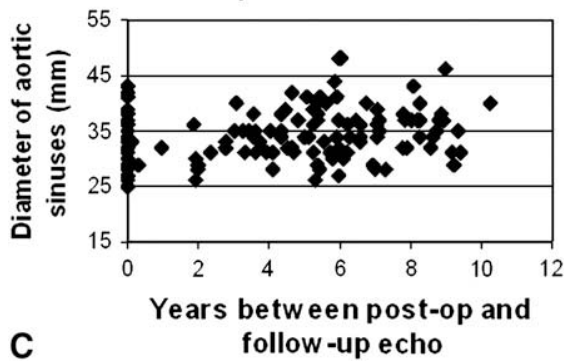

Size of implanted aortic valve $=25 \mathrm{~mm}$

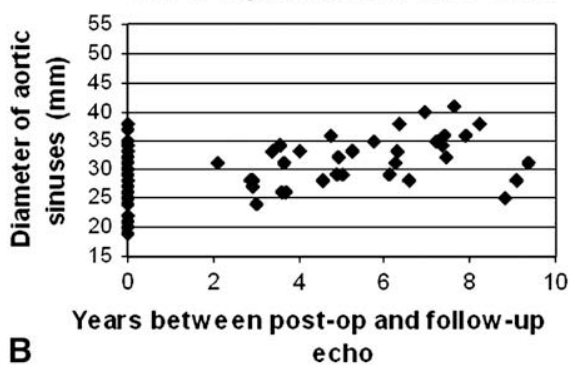

Size of im planted aortic valve $=29 \mathrm{~m} \mathrm{~m}$

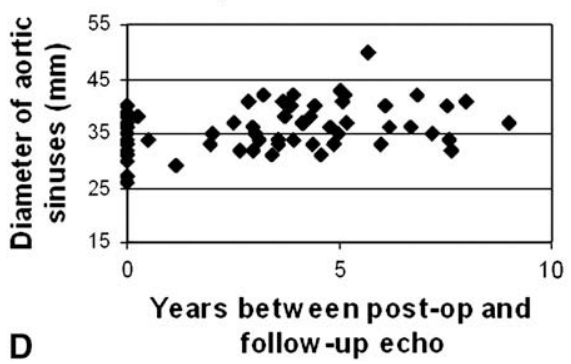

FIGURE 4. Changes in diameter of the aortic sinuses during follow-up. Zero indicates early postoperative diameters.

instances of ruptured Freestyle bioprostheses in 3 patients. Two patients had aortic valve replacement with a modified subcoronary implantation whereby the noncoronary aortic sinus of the porcine aortic root was left intact. One of these 2 patients died 51 months after the operation from rupture of the noncoronary sinus of the xenograft root, and the other patient also had a ruptured noncoronary sinus 20 months after the operation but had a successful reoperation. The third patient had ARR and false aneurysms caused by rupture of the left and noncoronary aortic sinuses of the xenograft root 17 months after the operation. The patient underwent reoperation with the same type of bioprosthesis, and it ruptured again 1 year later. There are 2 other case reports of rupture of the noncoronary aortic sinus of the xenograft root after aortic valve replacement with the modified subcoronary implantation, one by Kitamura and coworkers ${ }^{11}$ and the other by Takami and colleagues. ${ }^{12}$

In our experience with 308 patients, we documented early rupture of the aortic sinuses in only 1 patient: the noncoronary aortic sinus had a tear soon after completion of the procedure and was successfully treated with a pericardial patch. We do not believe that surgical trauma was the cause of rupture of the aortic sinus in this patient. Thus it is possible that the noncoronary aortic sinus was very thin because of excessive "shaving" of the soft tissue on the porcine aortic sinuses before fixation with glutaraldehyde during manufacturing and that a tear developed during a hypertensive episode.

This study documents that the diameter of the aortic sinuses of porcine roots decreases in a few patients, does not change much in most, and dilates in some, particularly when large-sized valves are used. Of 9 patients who had SVD, only in 2 patients did the valve fail because of aneurysm formation of the porcine aortic root. Isolated dilation of the aortic sinuses does not cause AI. ${ }^{14,15}$ The sinotubular junction must also dilate to pull the commissures away from each other to cause $\mathrm{AI} .{ }^{14,15}$ The reasons why the porcine aortic root dilates after implantation remain elusive. Based on our experience, not all porcine aortic roots dilate, and the degree of dilation varies widely, as seen in Table 3 and Figure 4. Larger valves seem to dilate more than smaller ones, or at least they are more likely to reach abnormal diameters $(>40 \mathrm{~mm})$. This is likely because of LaPlace's law. Interestingly, the operative technique (ARR or aortic inclusion technique) had no effect on dilation, probably because the

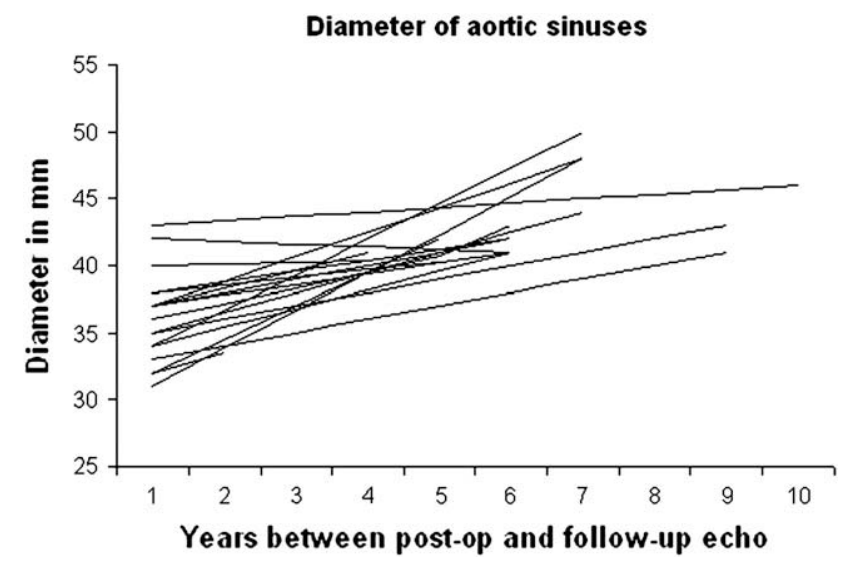

FIGURE 5. Changes in diameter in 20 patients with aortic sinuses of greater than $40 \mathrm{~mm}$ during follow-up. 

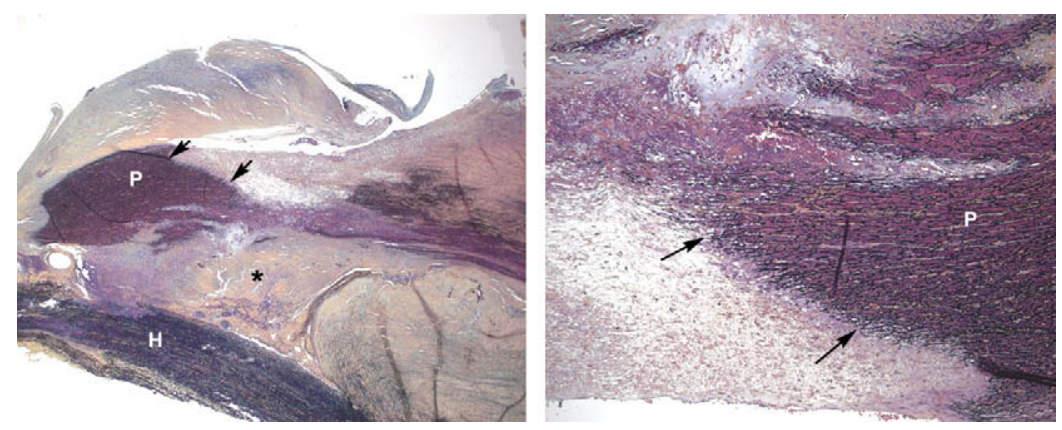

FIGURE 6. Left, This longitudinal section from an explanted Freestyle bioprosthesis shows the porcine aorta $(P)$, the host aorta $(H)$, and connective tissue deposited between the two. The porcine aorta shows multifocal destruction (“digestion") of tissue and replacement with connective tissue (*). Inflammatory cells are still present in the junctional areas between the porcine aortic media and the connective tissue (arrows). A thick layer of host tissue reaction is seen overlying the anastomosis of the porcine aorta with the host aorta. (Movat Pentachrome stain; original magnification, $\times 16$.) Right, A section of porcine aorta $(P)$ from an explanted Freestyle valve showing destruction of the media (arrows) and replacement by loose connective tissue. Inflammatory cells are seen in the junctional area. (Movat Pentachrome stain; original magnification $\times 100$ ).

native aortic root was dilated and diseased to start with in our patients. A small number of patients had CT scans, and we found that although all 3 aortic sinuses dilate, the noncoronary aortic sinus tends to dilate more than the other 2 aortic sinuses.

Butany and associates ${ }^{8}$ from our institution described the pathologic findings of 9 Freestyle valves explanted because of structural valve failure or endocarditis. They documented disruption of collagen and elastic plates in the arterial wall in most specimens, which ranged from scalloping of the media tissue from the inner, outer, or both sides to transmedial disruption, thinning of the wall, and formation of aneurysm. They also found chronic inflammatory cells inside of the xenograft arterial wall that were highly suggestive of immunologic reactions against the graft. In addition, the degree of damage to the arterial wall was proportional to the duration that the graft had been in the host.

Human and Zilla ${ }^{16}$ found that an incompletely fixed arterial wall with glutaraldehyde could be immunologically active and could incite humoral immune response. Moreover, Konakci and coworkers ${ }^{17}$ described an immunogenic $\alpha$-Gal epitope on fibrocytes interspersed in the connective tissue of porcine valves. Those investigators also found that patients with bioprostheses had significant increases of naturally occurring cytotoxic IgM antibodies directed toward $\alpha$-Gal after surgical intervention compared with control patients. ${ }^{18}$ Thus it is possible that in addition to increased mechanical stress to which large porcine aortic roots are subjected after implantation, incomplete fixation of the arterial wall of the xenograft might provoke an inflammatory reaction with destruction of the medial porcine aortic sinuses, as shown in Figure 6. Thus it is possible that an immunogenic reaction is partially responsible for dilation of the porcine aortic roots. Anecdotally, one of the patients described by Ozaki and colleagues ${ }^{10}$ had ARR with the Freestyle bioprosthesis twice; the first one ruptured after 17 months of implantation and the second after only 12 months. Although this might have occurred entirely by chance, it is possible that pre-existing antibodies against the xenograft arterial wall played a role in the digestion of the xenograft aortic sinus with consequent rupture. Clearly, further investigation in this area is needed.

In conclusion, rupture and aneurysm formation of the aortic sinuses of porcine aortic roots are rare complications of ARR during the first decade of follow-up. These complications can occur with both techniques: total ARR and aortic root inclusion. We continue to use the Medtronic Freestyle bioprosthesis for ARR when a bioprosthetic root is desirable. However, patients who have had ARR with porcine aortic roots must be followed with annual echocardiograms.

\section{References}

1. Bach DS, Kon ND, Dumesnil JG, Sintek CF, Doty DB. Ten-year outcome after aortic valve replacement with the freestyle stentless bioprosthesis. Ann Thorac Surg. 2005;80:480-6.

2. Kon ND, Riley RD, Adair SM, Kitzman DW, Cordell AR. Eight-year results of aortic root replacement with the freestyle stentless porcine aortic root bioprosthesis. Ann Thorac Surg. 2002;73:1817-21.

3. Cartier PC, Dumesnil JG, Métras J, et al. Clinical and hemodynamic performance of the Freestyle aortic root bioprosthesis. Ann Thorac Surg. 1999;67:345-9.

4. Gleason TG, David TE, Coselli JS, Hammon JW Jr, Bavaria JE. St Jude Medical Toronto biologic aortic root prosthesis: early FDA phase II IDE study results. Ann Thorac Surg. 2004;78:786-93.

5. Melina G, De Robertis F, Gaer JA, Amrani M, Khaghani A, Yacoub MH. Mid term pattern of survival, hemodynamic performance and rate of complications after Medtronic freestyle versus homograft full aortic root replacement: results from a prospective randomized trial. J Heart Valve Dis. 2004;13:972-5.

6. Melina G, Horkaew P, Amrani M, Rubens MB, Yacoub MH, Yang GZ. Three-dimensional in vivo characterization of calcification in native valves and in Freestyle versus homograft aortic valves. $J$ Thorac Cardiovasc Surg. 2005;130:41-7.

7. Mohammadi S, Baillot R, Voisine P, Mathieu P, Dagenais F. Structural deterioration of the Freestyle aortic valve: mode of presentation and mechanisms J Thorac Cardiovasc Surg. 2006;132:401-6.

8. Butany $\mathrm{J}$, Zhou T, Leong SW, et al. Inflammation and infection in nine surgically explanted Medtronic Freestyle stentless aortic valves. Cardiovasc Pathol. 2007; 16:258-67.

9. Kameda Y, Mizuguchi K, Kuwata T, Mori T, Taniguchi S. Aortopulmonary fistula due to perforation of the aortic wall of a freestyle stentless valve. Ann Thorac Surg. 2004;78:1827-9. 
10. Ozaki N, Hino Y, Hanafusa Y, et al. Perforation of the Valsalva sinus after implantation of Medtronic Freestyle aortic bioprosthesis. Ann Thorac Surg. 2006;82:2282-5.

11. Kitamura A, Handa N, Shomura Y, et al. Reoperation for early failure of a freestyle bioprosthesis using a full root technique. J Heart Valve Dis. 2007;16:275-7.

12. Takami Y, Masumoto H, Fyfe-Kirschner B. Late disruption of a Freestyle stentless bioprosthesis used for repair of sinus of Valsalva aneurysm of noncoronary cusp. Ann Thorac Surg. 2007;83:2210-3.

13. Mohammadi S, Baillot R, Voisine P, Mathieu P, Dagenais F. Structural deterioration of the Freestyle aortic valve: mode of presentation and mechanisms. J Thorac Cardiovasc Surg. 2006;132:401-6.
14. Bach DS, Kon ND, Dumesnil JG, Sintek CF, Doty DV. Eight-year results after aortic valve replacement with the Freestyle stentless bioprosthesis. J Thorac Cardiovasc Surg. 2004;127:1657-63.

15. David TE. Surgery of the aortic valve. Curr Probl Surg. 1999;36:421-504.

16. Furukuwa K, Ohteki H, Cao ZL, et al. Does dilatation of the sinotubular junction cause aortic regurgitation? Ann Thorac Surg. 1999;68:949-54.

17. Human $P, Z$ Zilla $P$. Characterization of the immune response to valve bioprostheses and its role in primary tissue failure. Ann Thorac Surg. 2001;71:A385-8.

18. Konakci KZ, Bohle B, Blumer R, et al. Alpha-Gal on bioprostheses: xenograft response in cardiac surgery. Eur J Clin Invest. 2005;35:17-23. 